\title{
Treatment of Attachment Traumas in Postpartum Depression with Intensive Short-Term Dynamic Psychotherapy: Addressing the Self-Critical Personality
}

Elke Schlager*

Psychotherapist, Fielding Graduate University, Reston, USA

*Corresponding author: Elke Schlager, Psychotherapist, Fielding Graduate University, Reston, USA, E-mail: elkeschlager@gmail.com

Received date: November 5, 2016; Accepted date: November 25, 2016; Published date: December 2, 2016

Copyright: (c) 2016 Schlager E. This is an open-access article distributed under the terms of the Creative Commons Attribution License, which permits unrestricted use, distribution, and reproduction in any medium, provided the original author and source are credited.

\begin{abstract}
Intensive Short-term Dynamic Psychotherapy (ISTDP) is a treatment that has shown promise in addressing attachment ruptures that lie at the root of postpartum depression (PD). ISTDP can provide rapid symptom relief while also addressing the underlying maladaptive personality structures that cause and prolong PD. These vulnerabilities can include self-neglect, harshness toward the self and others, and difficulty regulating emotions. Research has shown that this self-critical personality style, usually resulting from having distant or harsh parenting, is highly correlated with PD. ISTDP directly addresses these self-critical patterns, commonly referred to in the psychodynamic literature as "superego pathology". These patterns are thought to result from the identification with harsh caregivers. A woman may doubt her capacity as a caregiver, push away supports, minimize or ignore her feelings, project her fears and anger onto the baby, dismiss her instincts and idealize authority figures. If these tendencies are not addressed, a woman is likely to pass along these enduring patterns to her baby and future generations. Early, rapid, and effective psychotherapy treatments that address these underlying non-conscious defense mechanisms are essential in healing PD and ensuring a positive mother-infant bond.
\end{abstract}

"If we want to shape the future, to truly improve the world, we have 1,000 days to do it, mother by mother, child by child. For what happens in those 1000 days through pregnancy to the second birthday determines to a large extend the course of a child's life...".

\section{Introduction}

Postpartum Depression affects $10-20 \%$ of middle class women worldwide [1]. The rates may double or triple when other risk factors are present, such as poverty, relocation, or medical problems during pregnancy [2-5]. As alarming as these rates may seem, they may underestimate the prevalence of $\mathrm{PD}$, since up to $50 \%$ of all postnatal depressed cases go undetected and untreated [6]. When PD goes untreated, it extends the duration of the depression and causes farreaching adverse effects to the mother, the infant, and the relationship with her partner [7]. Untreated PD may seriously damage the maternal-infant interaction during the first year after delivery, which results in cognitive, emotional, and behavioral deficits in the child $[6,8-10]$.

Research over the past decade has demonstrated that the period from pregnancy through the first two years of life is by far the most important developmental window in a child's life. These first 1,000 days affect the child's ability to "grow, learn, work, succeed-and, by extension, the long-term health, stability, and prosperity of the society in which that child lives" [11]. A depressed mother tends to be withdrawn and unavailable to her children, have fewer supports, be more concerned with her own mental health problems, and have more frequent hospitalizations [2]. Being born to a depressed mother puts the child at significant risk for later psychopathology, including problems with impulse control, working memory, and disorders related to emotion dysregulation [12]. In addition, the offspring of depressed mothers are negatively affected in a variety of ways, including preterm birth, low birth weight, newborn irritability, developmental delays, somatic complaints, increased risk of infant hospitalizations, sleep problems, and neurobehavioral disorders [2,10,13-17].

Every mother who gets depressed in the pre- and postpartum period represents a medical and mental health emergency, since not only the mother is affected but the future wellbeing of her newborn child. Given the high prevalence rates, the short developmental window of the first two years, and the long-term negative consequences of untreated PD, we urgently need treatments that will work quickly, deeply, and effectively to ameliorate the symptoms, while minimizing relapse rates for future depressions.

Much of the impetus over the past decade to find a cure for PD has focused on biological factors, such as hormonal and neurotransmitter changes following pregnancy. Specifically, the sharp drop in estradiol levels following childbirth has been hypothesized to have an association with PD [18]. However, there appear to be no significant differences between depressed and non-depressed subjects in the ratios of estriol or estradiol levels [19]. Similarly, there are no controlled studies that exist to date that can confirm the relationship between progesterone declines and PD [20]. Moreover, progesterone treatments have not proved effective in treating PD [19,21]. On the other hand, the normative depressive symptoms that occur immediately after delivery, commonly referred to as "baby blues," appear closely linked to hormonal factors. Baby blues occurs in $80 \%$ of women and usually resolves within two weeks [22]. Symptoms that persist beyond two weeks are more often correlated with psychological factors [22,23]. In summary, no research to date has substantiated the hypothesis that PD is related to hormonal changes. 
Although few randomized control trials have been conducted, it seems that psychopharmacological treatments can alleviate the symptoms of PD [24]. However, there is no evidence that medications have any lasting effect once they have been discontinued [25] Moreover, the vast majority of women refuse to take anti-depressant medications due to their effects on the fetus during pregnancy and after birth through lactation.

While no study has linked antidepressants to birth defects, medications can alter the normal development of the fetus. Research has demonstrated that fluoxetine causes respiratory problems, cyanosis on feeding, low birth weight and shorter length at birth [26]. Structured behavioral and neurological assessments of newborns have shown changes in brain activity when comparing infants with SRI exposure with a control group [27]. SSRI exposure during pregnancy is also associated with preterm birth, a low five-minute Apgar score, and admission to the neonatal intensive care unit. One study noted that NICU admissions were often related to withdrawal from or adverse effects of SSRIs, including jitteriness, seizures, respiratory problems, infections, and jaundice [28].

\section{Psychotherapy for Postpartum Depression}

With the above concerns, psychotherapy should be the frontline treatment for PD. A small number of clinical trials have been conducted to test several short-term manualized treatments on women during the postpartum period (Interpersonal Psychotherapy (IPT), Cognitive Behavioral Therapy (CBT). Psychodynamic Psychotherapy and educational interventions were also tested, as well as different therapies in combination with medication. All treatments were found to be effective in alleviating symptoms in the short-term, with therapy trials in combination with medications having the largest effect sizes [29].

Given the limited number of trials and methodological weaknesses of current research (e.g., small N), more research needs to be done. On the other hand, Bledsoe and Grote suggest that the treatment of major depression in women during pregnancy and the postpartum is very similar to the treatment of depression at other times in the life cycle.

One limitation facing current manualized treatments (6-16 sessions) for general depression, such as CBT and IPT, is the high relapse rates. In fact, in the most comprehensive research program for depression conducted thus far (National Institute of Mental Health Treatment of Depression Collaborative Research Program (NIMHTDCRP)), $78-88 \%$ of patients in these treatments either relapsed or sought further treatment at the end of their treatment trial [30]. CBT has addressed this problem in recent years by introducing continued follow-up sessions to prevent the recurrence of depression. However, research indicates that preventing future depressive episodes requires long-term and frequent maintenance treatments [31]. This begs the question of whether a short-term treatment that requires long-term and frequent maintenance sessions can legitimately be called "short term." It is certainly likely that some depressive disorders never remit entirely and require long-term maintenance treatment. However, it also could be true that these short-term treatments do not go deep enough in addressing depression at the core to provide enduring change.

Patients who have the greatest risk for relapse and recurrence include patients with personality disorders, multiple prior depressive episodes, childhood trauma, or early age of onset [31,32]. Patients with a significant prior history of depression and those with comorbid personality disorders are more likely to have residual depressive symptoms at the end of a trial of cognitive therapy, or unstable remission, which appears to put them at risk for relapse.

\section{A New Emerging Paradigm in Psychotherapy}

Cutting-edge psychotherapy treatments over the past decade are integrating neuropsychiatric research, which is revealing that a wide array of psychiatric disorders originate in the dysregulation of the limbic and autonomic nervous system. Attachment pathology from early abuse and neglect causes alterations in the developmental trajectory of the right brain. Specifically, a large body of research is showing that the control system of attachment, which is centered in the orbitofrontal cortex of the right brain, develops more rapidly in the first two years of life than the verbal left side and is dominant in the first three years of life $[11,33]$. Given this new understanding of the neuropsychiatric basis of psychopathology, it is clear that psychotherapeutic changes in conscious cognitions alone without changes in emotional processing are going to be limited. Accordingly, the focus in newer clinical models is shifting to right brain bodilybased emotions, which addresses the autonomic nervous system stimulating visceral experience of emotion thought to be at the core of attachment pathology.

\section{Personality Factors and Postpartum Depression}

When early attachment experiences have been painful, the transition to motherhood can be quite stressful and may activate implicit memories of what she did and did not receive from her caregivers. The appraisal of these relationships is critical for any woman in defining her values, parenting style, and trusting her instincts as a mother. Going through this emotional inventory (which is only partly conscious) often activates an array of feelings that a woman needs to work through to be emotionally ready to nurture herself and her new baby. However, when the feelings that emerge are painful or conflicting (e.g. guilt about anger) it will generate anxiety, which a woman will unconsciously cover up through defensive strategies. She may doubt herself, push others away, minimize or ignore her feelings, cut off emotionally from her partner or her baby, project her fears and anger onto the baby, or dismiss her instincts and idealize authority figures [34]. The inability of a woman to bear these conflicting emotions and the accompanying anxiety appears to be at the core of PD. Without an internal emotional compass to guide her, a mother may have a hard time nurturing herself and her new baby and be lost in navigating the new challenges of motherhood.

Cognitively, most new mothers can understand that the care of a newborn is going to involve sacrifice: sleepless nights, changing diapers, being at the beck and call of a vulnerable infant, while having to rely on a support network for relief. However, at a visceral, limbicsystem level, the baby's cries and unceasing demands can trigger a cascade of stress and complex feelings in the mother. There is no instruction manual or course that prepares a woman for the mixed feelings of love, sadness, and anger that she may experience in these first weeks and months after giving birth. Unprepared for this rise of emotions, the new mother may be overcome with inhibitory emotion of guilt or shame, and wonder: "Am I a good mother?" For many mothers the answer always falls short of their ideal of what a good mother should be. Any small mistake can be amplified and focused upon as proof that they are not up to the task. 
In a qualitative study, I conducted with new mothers on resilience and vulnerability to $\mathrm{PD}$, one participant described motherhood as:

"A vicious cycle that starts and ends in the same place... for example if I am with my baby playing and all of the sudden I forgot something important to give him, such as his vitamins, which I used to forget, and at night I remembered, then I would not sleep at night with a terrible feeling of guilt, and the next day again, I would wake up saying, today I'll do it right, until I commit another mistake" [34].

There is a strong tendency for anger to be denied by depressed mothers and experienced as self-criticism, particularly when those feelings are directed toward the baby [35]. Cultural factors may contribute to this tendency, given the societal expectations that the birth of a baby should be a time of pure joy and contentment. Women prone to self-criticism may judge themselves harshly for having conflicting feelings.

This anger toward the self can take many forms, but in modern society it tends to be expressed in work and family issues. Whether a mother decides to go back to work or to become a full-time mother, declaring her choice can lead to a minefield of questioning, rumination, and dissatisfaction:

"Not that I'm saying that I am unhappy, the feeling that I want to do this but I can't, even to go out somewhere, I can't!... I feel like I am stranded. I miss it (being independent) very much, like I'm tied up, I can't do anything else. I do not agree with being a stay-at-home mom. ... It is not that I am unhappy. Do you understand the feeling? I just want to do something more productive. It's not that what I have with my child is not productive" [34].

Another mother judged herself for not spending enough time with her baby.

"I know this is what I want, it's clear, to spend time with my baby while she is still developing. However, I worry, would I be a good mother if I am with her full time? Or would she be better off with a full time nanny?

This participant worried that if she gets what she wants she might not enjoy it, or underestimates herself by questioning whether she has the capacity to be a nurturer for her daughter. This indecision and selfdoubt is the hallmark of anger turned inward. This harshness toward the self appears to be based on unconscious identifications with parents or other caretakers. These identifications with caretakers occur at a very young age when the child is completely vulnerable and dependent. When a parent damages the bond with the young child, the child may feel reactive rage [36-38]. Since expressing this rage would be damaging to the bond with the parent (or even dangerous to the child's survival), the child will turn the rage on herself (as a result of unconscious guilt), thus protecting the bond with the parent. The tendency to turn anger inward can become a core dynamic in the way the child comes to treat herself, her relationships, and her feelings.

Similarly, other identifications with the parent can be internalized and enacted collectively as a set of defenses [39]. These enactments serve the purpose of warding off the anger that could not be experienced at an earlier time when she was dependent on that caregiver. For example, if the parent chronically ignores or devalues the child's emotions, the child may grow up neglecting themselves and their internal experience out of identification with the parent. Alternatively, they may enact the identification by neglecting their baby or husband in the way they were neglected themselves. Finally, a woman can enact identification with her parent by projecting her anger onto others and feel that they are criticizing or neglecting her.

One woman in my study, who described her father as having a bad temper and being aggressive toward her and her mother, was afraid of being too much like her father, and thus fearful of her own aggression:

"Maybe I am too strict; my father brought me up like that. For me, there is no middle of the road, either you're good or you're bad. My father has always been that way. There are no gray areas."

Her fears about her own aggression led her to push away her baby, describing the baby as a "porcelain doll" who could easily break because of her "roughness" and "incompetence." As a result, she delegated much of the parenting to her husband who she viewed as the gentle, soothing parent. Most of the evidence indicated that this woman was very kind and competent as a mother, but her unconscious identification with the father paralyzed her from exercising her competence.

The collection of identifications with a parent has been referred to as superego pathology [39]. In psychodynamic theory the superego is thought to provide "a conscience, a capacity for guilt, a moral sense of what is right and wrong that gives meaning to our lives, an ideal image toward which we strive, or inner voice saying we should not do something" [40]. However, when parenting is harsh and critical, or when the attachment bond is ruptured through abuse or neglect, the child internalizes this harshness and self-criticism and unconsciously enacts these identifications by depriving, hurting, self-sabotaging, or punishing themselves or others [40]. In this way, anger is not experienced toward the significant other, but is turned back on the self in a punishing way, often resulting in clinical depression. When this superego pathology is severe, a mother may think of herself as bad, evil, or innately unlovable.

Repairing Attachment Ruptures through Intensive Short-term Dynamic Psychotherapy (ISTDP). One model of in-depth treatment that focuses specifically on repairing attachment ruptures that are at the root of this superego pathology is Intensive Short-term Dynamic Psychotherapy (ISTDP). Developed by Canadian researcher, Habid Davanloo, ISTDP evolved out of psychoanalytic theory in response to growing concerns that psychoanalysis was becoming too lengthy, too intellectual, and insufficiently attentive to the mobilization of the patient's will [41]. This model views psychopathology as primarily resulting from the ways that people use psychological defenses to avoid emotional experiences and to block interpersonal connection. These defenses are seen as protective responses to traumatic or neglectful attachment experiences, which become overgeneralized in other contexts.

One primary goal in ISTDP is to build the patient's capacity for affect experiencing (AE). AE is considered a fundamental catalyst for change. Specifically, the focus of treatment is on developing awareness of the present moment patient's bodily experience of emotion. The deeper the experience of effect on a physiological level, the more thorough the desensitization process will be [42]. Neurologically, AE has been shown to open the pathways to unconscious, non-verbal right brain learning, responsible for producing deep lasting change. ISTDP is an experiential psychodynamic therapy that encourages in-session visceral experiencing of emotion that may have been repressed, denied, or minimized in some way. The experience of the full range of mixed feelings, both with significant others and with the therapist, is considered the primary change mechanism in this therapy. 
There is a large body of research that demonstrates the effectiveness of ISTDP in treating a broad range of clinical disorders, including personality, depressive, anxiety, and medically unexplained symptoms [43-46]. These mental conditions are thought to be related to adverse childhood experiences (ACE), which are associated with changes in brain structure and function and stress-responsive neurobiological systems [47]. Conditions arising from ACE are considered to be byproducts of strong unprocessed emotions coupled with deficits in capacity to regulate emotions $[11,48]$.

Micro-analysis of single-case research on PD has shown very similar patterns of treatment and recovery to most other cases of depression. The superego pathology in PD merely takes a slightly different form, in that the content of treatment focuses more on a woman's identity as a mother and how her early attachments inform her feelings about herself as she take on the new role. Otherwise, treatment follows very similar patterns to other ISTDP treatments.

The ISTDP method allows the therapist to identify the core emotional conflicts, usually within the first couple of hours of treatment. In this "trial therapy" the therapist addresses defenses and resistance as early as the first moments of treatment. Whereas, a longterm dynamic therapy tends to focus the first few sessions on history taking, ISTDP focuses from the beginning moments of treatment on: 1) defenses that block the experience of emotion; 2) regulating anxiety as defenses are addressed; 3 ) helping the patient experience their core feelings as deeply as possible; 4) addressing resistance that emerges during this rapid uncovering of feeling. In this in-vivo assessment, the goal is to assess the patient's tolerance for bearing emotion, ability to regulate anxiety, and the systems of defense that they utilize when under stress. The patient emerges from the initial session with a deeper understanding of their core emotional conflict, including the cause and effect relationship between the defenses that block emotions and the symptoms that cause her suffering.

Below I will describe a case vignette of PD that was treated with ISTDP. This case will demonstrate how the therapist can address defenses and help the patient turn against these defenses to reach the buried mixed feelings. These vignettes show how this process begins from the very moment a patient enters the therapy in order to alleviate suffering as rapidly as possible.

\section{The Case of Laura}

Laura is a 34 year-old woman who recently gave birth to her second child. About one month after delivery, she began having sleeplessness, irritability, rumination, guilt, and panic attacks. She could not rid herself of the irrational thought that a tree would come down in a snowstorm and crush her and her baby. Her husband brought her to the appointment. The following is the first few minutes of the initial evaluation.

Th: What's the internal emotional conflict you want me to help you with?

PT: (With red eyes, looking at the floor, she blurted out) I'm ashamed to admit this, but I have a fear that trees near my house can fall and hurt my family!

\section{Th: When did this fear begin?}

PT: It started a month ago after my delivery. It was the day after the big snowstorm. My husband was on a business trip and I stayed alone with my two children. My anxiety is so bad, I can't sleep, and I can't stop thinking and thinking (hands trembling and rapid speech).

Th: (speaking very slowly and deliberately) If we slow down for a moment, how do you notice this anxiety right now here with me? (Inviting her to notice her anxiety instead of ignoring it).

Pt: (still pressured) Yes, I feel anxious speaking about it. I can't understand what is happening to me. Why is it that I can't stop thinking about this? It's torture!

Th: If we put the questioning to the side, and attend to this anxiety first, where do you experience this anxiety physically in your body?

PT: Here in my chest. My chest and stomach feels tight.

Th: What else to you notice in your body?

Pt: My heart is beating fast and my neck feels tense. Also my jaw feels in pain since I bite so hard.

Th: Very good that you are noticing all of this. Would you like to find out what the feelings are that are triggering this anxiety?

Pt: Yes of course, I want. But you have to admit this is crazy!

Th: What is crazy?

Pt: I am crazy, to feel so afraid of everything. But even worse taking care of two children (self-attack and projection, inviting me to judge her). I never disliked snow or winter. I thought I could overcome this by myself, but here I am. (Like many women with a self-critical personality type, she has a conflict about accepting help).

Th: So you've mentioned several times that I must think you're crazy. As we're getting started here, is there any sense that I am judging you, or perceiving you as crazy?

Pt: Well, you see people who are crazy all the time, so I guess you can deal with it.

Th: Right. As you look at me, what's the evidence that I am judging you?

Pt: (looks up) No, it's not you. I'm always irritated like this and thinking the worst of people. My husband tells me that all the time.

Th: Could this perception that people are judging you cause you to push people away?

Pt: Yes, I do that all the time. I don't have a lot of friends who I really let in.

Th: So, if we bring this here with me, what would it be like to allow me to help you here today?

Pt: Yes, I'm very independent. I don't usually let people help me. But these fears are driving me crazy. I really need you to help me.

Th: Notice how that feels to say that: I want you to help me.

Pt: It's weird to say, but it feels positive. I want to get rid of these thoughts that are making me so irritated with everything!

Th: Tell me more about the irritation.

Pt: I am cranky and irritated with everybody; I do not like to be like this.

Th: I wonder, do you notice any of this irritation here right now.

Pt: Yes, it's always there. 
Th: Since you say everybody, and I am no exception, do you notice it here with me?

(Given that she judges herself in my presence and she said this is a constant feeling, I am inviting her to channel this feeling towards me instead of hurting herself-inviting transference of feelings. Inviting transference feelings in the here-and-now at this early stage of therapy is unique to the ISTDP approach).

Pt: But I'm not angry (she introduces her anger, even as she negates it by saying she is not angry)

Th: You are telling me what you do not feel. However, what is the feeling?

Pt: Well, but it's not with you. To be honest I do not like doctors. I saw a doctor a month ago and he told me that I was very depressed and recommended medication. I do not want to take it because I am breastfeeding. She scared me so bad when she told me that if I did not take it I was in danger of hurting my baby or myself. When she said that I wanted to run. I never went back. But now I cannot let her words out of my mind. What if she is right and I am in danger to hurt my boy? (She has feelings toward her doctor that trigger anxiety, that are feeding her self-attack and self-confidence. She is also referring to transference of feelings towards me, given that I am the doctor she is seeing at this time.).

Th: If we put those self-doubts to the side (blocking the defense of self-doubt), I wonder what feelings do you have towards the doctor for insinuating that you are a danger to your baby? (Helping her direct her anger towards the doctor and away from herself).

Pt: I think he was wrong to say that to me. Don't you agree? (She answers with a thought, then doubts herself and looks for my approval).

Th: That is your thought, but what are the feelings towards the doctor for saying that you are a danger to your baby?

Pt: I feel very disappointed (confuses the stimulus, what the doctor did to her, from her feeling towards the doctor).

Th: He disappointed you with what he said to you. But what is the feeling toward him for disappointing you?

Pt: I am not angry (pauses), well, maybe a little.

Th: A little? Do you notice how you minimize your feeling?

Pt: (deep sigh, with strong and decisive voice), well, yes, very angry because he added another layer of fear that I did not have before I entered his office.

Th: Where do you feel your anger physically in your body? (Inviting her to activate the visceral experience of emotion in the present moment).

Pt: I experience a lot of tension in my neck and shoulders. I am feeling a little bit of a headache.

Th: Tension in your neck, a headache, this is anxiety. Can you feel your anger towards her underneath this anxiety? (Helping her differentiate her feelings of anger, from the anxiety that inhibits it).

Pt: But why am I so angry with this doctor? (Rationalizing her feelings).

Th: If we put those questions aside, how do you experience that anger physically in your body? (Inviting her to feel her feelings).
Pt: There is a sensation of tension in my arms and warmth in my shoulders and pressure in my jaw (the patient gives a big sigh, which indicates that her anxiety is located in the striated or skeletal muscles, which is a "go signal" in ISTDP, indicating that we can continue deepening this feeling of anger. Other types of anxiety, such as dizziness or nausea, would indicate that we would need to slow down and work on regulating the anxiety instead. However, since her anxiety is in a therapeutic range, we continued with this exposure to feelings at the doctor.).

Through feeling this anger toward her psychiatrist, she recalled anger toward another doctor, the OB/GHN who delivered her firstborn child three years before and informed her that her son had Down syndrome.

Pt: The news hit me like a thunderbolt. I did not have the slightest idea because I decided not to do the genetic test. Neither the doctor nor the nurse brought him to me to see him. I felt in shock, devastated and helpless because I could not move, I felt so vulnerable in front of these doctors. Nevertheless, it angers me to recall how they told me that my son was not going to be able to do much in life.

She was able to experience some anger at the doctor who treated her roughly without turning it on her, by feeling ashamed of having a child with Down syndrome. Experiencing these feelings of anger opened the door to her grief and guilt.

Th: And now what is the feeling? (Tears rolling down her cheeks, sighing deeply).

$\mathrm{Ph}$ : Deep, deep sadness. For what my son and I went through, and also feel guilt for being so harsh with him and myself all this time. Very sad (sighing deeply)

Th: Let yourself have this feeling. The deeper you feel these painful feelings, the more you will be healed.

The patient cried deeply for a few minutes, feeling a mixture of grief and guilt.

The shock of having a baby with Down syndrome and the way she received the news was traumatic for Laura, which became the primary focus of treatment. Directing the feelings of anger towards the doctor for the treatment she received from them revealed hidden emotions grief, guilt, and anger towards her son. She admitted that even if she professes great love for her son, on occasions, she wanted to reject him and sometimes she wished she never had him. Instead of facing her guilt as a feeling, which she could not tolerate, it turned into selfattack, calling herself a "bad mother." Therefore, she punished herself and her son by being harsh toward him, which started a vicious cycle. Self-punishment tends to inhibit feelings of love, forgiveness, and selfcompassion, which in her case deprived her of enjoying her new baby. Finally, Laura was able to access unconscious memories and emotions towards her primary caretakers, who also treated her in a harsh and distant manner at moments when she was anxious and vulnerable. Her internalized anger became a part of her personality that emerged in childhood, and was then activated after giving birth and resulted in postpartum depression. Symbolically, the snowstorm was an event that reactivated her experience of feeling out of control and helpless like she felt in the hospital bed when she received the painful news about her son's Down syndrome. Laura's depression remitted after 4 sessions. She completed her treatment in 18 sessions. 


\section{Conclusion}

The passage to motherhood presents a unique opportunity for a woman to rework emotional issues from her own upbringing that may interfere with her ability to parent and trust her instincts as a mother. This is a time when a woman's early attachment experiences often come to the surface, as the challenges of caring for a newborn can open a floodgate of confusing feelings. The psychological conflicts and identity issues that arise in the new mother can overwhelm a woman's emotional capacities, often triggering clinical depression and anxiety. This emotional dysregulation tends to interfere with a woman's emotional capacity to develop a secure attachment bond with her child. While there are many factors that can impact a child during this period, the development of a secure bond with a primary caregiver will become an imprint that directs her response to stressful events for the rest of her life. When mothers become depressed, they tend to withdraw emotionally and be unable to respond to the needs of their children, damaging the mother-infant bond and causing cognitive, emotional, and behavioral deficits.

One parental attachment failure that has been associated with depression that transfers from one generation to the next is selfcriticism [48]. Specifically, vulnerability to maternal depression is highly correlated with traits of self-criticism and having an insecure attachment style [34]. Self-critical mothers are prone to having significant anger toward themselves and significant others and placing excessive demands on themselves. They may also feel that they are failing to meet an ideal of what they believe a good mother should be. Building a woman's capacity to bear frustration, contain it, and not turn it on one's self or other's (e.g., spouse or baby) is one of the most demanding developmental tasks of becoming a mother [34].

Psychotherapy needs to be a frontline treatment for PD, given mothers' reluctance to take medications during pregnancy or lactation. Given the importance of the first two years of a baby's development and the long-term negative consequences of untreated maternal depression, we need treatments that work quickly, deeply, and effectively to eliminate depressive symptoms in the new mother and that minimize relapse rates. Intensive Short-term Dynamic Psychotherapy (ISTDP) is a treatment that specifically addresses the attachment ruptures that may contribute to deficits in the ability to regulate anxiety, capacity to handle stress, and access supports. With this active form of emotion-focused psychodynamic therapy, many patients achieve meaningful symptom relief in the first two to three hours of therapy. Abundant research has shown ISTDP to be an effective treatment for a wide spectrum of clinical disorders, including depression, anxiety, and personality disorders. When personality factors complicate treatment, ISTDP has been shown to be effective where other treatments for depression have failed [46]. While treatment length is variable depending on the patient's level of psychopathology, many patients are able change long-standing maladaptive personality characteristics in approximately 20-40 sessions. Case studies of PD indicate that women respond to this treatment in a very similar way to other depressions. More research is needed to corroborate these clinical findings of the effectiveness of ISTDP for PD, and to see whether there are specific modifications that are indicated for working with depressed mothers.

\section{Ethical Approval}

The study referenced in this article used human participants. The women in the study, "Resiliency and Vulnerability to Postpartum
Depression in Acculturating New Mothers, " signed an informed consent granting permission for the use of "disguised interview material" if published in a professional journal. No identifying information was included in this article and material was disguised. Study was in accordance with the ethical standards of the institutional committed of Fielding Graduate University, which align with ethical standards of the American Psychological Association and the 1964 Helsinki declaration and later amendment to ethical standard.

\section{References}

1. Milgrom J, Martin PR, Negri LM (1999) Treating postnatal depression: A psychological approach for health care practitioners. New York: John Wiley \& Sons.

2. Chung EK, McCollum KF, Elo IT, Lee HJ, Calhane JF (2004) Maternal depressive symptoms and infant health practices among low-income women. Pediatrics 113: 523-529.

3. Hobfoll SE, Ritter C, Lavin J, Hulsizer MR, Cameron RP (1995) Depression prevalence and incidence among inner-city pregnant and postpartum women. J Consult Clin Psychol 63: 445-453.

4. Seguin L, Potvin L, St-Denis M, Loiselle J (1999) Depressive symptoms in the late postpartum among low socioeconomic status women. Birth 26: 157-163.

5. Martinez-Schallmoser L, Telleen S, Macmullen NJ (2003) The effect of social support and acculturation on postpartum depression in Mexican American Women. J Trans Nurs 14: 329-338

6. Beck CT, Gable RK (2000) Postpartum depression screening scale: Development and psychometric testing. Nurs Res 49: 272-282.

7. Miller RL, Pallant JF, Negri LM (2006) Anxiety and stress in the postpartum: is there more to postnatal distress than depression? BMC Psychiatry 24: 6-12.

8. Field T (1995) Infants of depressed mothers. Infant Behavior and Development, 18: 1-13.

9. Field $T$ (1998) Maternal Depression effects on infants and early interventions. Prev Med 27: 200-203.

10. Field T, Diego M, Hernandez-Reif M (2006) Prenatal depression effects on the fetus and newborn: A review. Infant Behav Dev 29: 445-455.

11. Thurrow R (2016) The first 1,000 Days: A crucial time for mothers and children and the world. New York: Public Affairs.

12. Schore A (2001) Effects of secure attachment relationship on right brain development, affect regulation, and infant mental health. Infant Mental Health Journal 22: 7-66.

13. Hiscock H, Wake M (2001) Infant sleep problems and postnatal depression: a community-based study. Pediatrics 107: 1317-1322.

14. Lee CM, Gotlib IH (1989) Maternal depression and child adjustment: A longitudinal analysis. J Abnorm Psychol 98: 78-85.

15. Orr ST, James SA, Blackmore-Prince C (2002) Maternal prenatal depressive symptoms and spontaneous preterm births among African American women in Baltimore. Am J Epidemiol 156: 797-802.

16. Orr ST, Miller CA (1995) Maternal Depressive symptoms and the risk of poor pregnancy outcome Review of the literature and preliminary findings. Epidemiol Rev 17: 165-171.

17. Weissman MM, Wickramaratne P, Nomura Y, Warner V, Verdeli H, et al. (2005) Families at High and Low Risk for Depression: A 3-Generation Study. Arch Gen Psychiatry. 62: 29-36.

18. Miller LJ (1999) Postpartum mood disorders. Washington, DC.: American Psychiatric Press.

19. O'Hara MW, Schlechte JA, Lewis DA, Varner MW (1991) Controlled prospective study of postpartum mood disorders: Psychological, environmental, and hormonal variables. J Abnorm Psychol 100: 63-73.

20. Hendrick V, Altshuler LL, Suri R (1998) Hormonal Changes in the Postpartum and Implications for Postpartum Depression. Psychosomatics 39: 93-101. 
Citation: Schlager E (2016) Treatment of Attachment Traumas in Postpartum Depression with Intensive Short-Term Dynamic Psychotherapy: Addressing the Self-Critical Personality. Clinics Mother Child Health 13: 251. doi:10.4172/2090-7214.1000251

Page 7 of 7

21. Heidrich A, Schleyer M, Springler H, Albert P, Knoche M, et al. (1994) Postpartum blues: relationship between not-protein bound steroid hormones in plasma and postpartum mood changes. J Affect Disord 30: 93-98.

22. Cutrona CE (1983) Causal attributions and perinatal depression. J Abnorm Psychol 92: 161-172.

23. Buchwald J, Unterman R (1982) Precursors and predictors of postpartum depression: A retrospective study. J Prevent Psychiatry 1: 293-308.

24. Payne JL (2007) Antidepressant use in the postpartum period: Practical considerations. Am J Psychiatry 164: 1329-1332.

25. Hollon SD, DeRueis RJ, Shelton FC, Amsterdam JD, Salomon RM, et al. (2005) Prevention of relapse following cognitive therapy vs. medications in moderate to severe depression. Arch Gen Psychiatry 62: 417-422.

26. Chambers CD, Johnson KA, Dick LM, Felix RJ, Jones KL (1996) Birth outcomes in pregnant women taking fluoxetine. N Engl J Med 335 1010-1015.

27. Videman M, Tokariev A, Saikkonen H, Stjerna S, Heiskala H, et al. (2016) Newborn brain function is affected by fetal exposure to maternal serotonin reuptake inhibitors. Cereb Cortex 1093: 153-156.

28. Lund N, Pedersen LH, Henriksen T (2009) Selective Serotonin Reuptake Inhibitor Exposure In Utero and Pregnancy Outcomes. Arch Pediatrics Adolesc Med 163: 949-954.

29. Bledsoe SE, Grote NK (2006) Treating depression during pregnancy and the postpartum: A preliminary meta-analysis. Research on Social Work Practice 16: 109-120.

30. Elkin I, Shea MT, Walkins JT, Imber SD, Sotsky SM, et al. (1989) National Institute of Mental Health treatment of depression collaborative research program: General effectiveness of treatment. Arch Gen Psychiatry 46 971-982.

31. Hollon SD, Thase ME, Markowitz JC (2002) Treatment and prevention of depression. Psychological Science in the Public Interest 3: 39-77.

32. Bockting CL, Hollon SD, Jarrett RB, Kuyken W, Dobson K (2014) A lifetime approach to major depressive disorder: The contribution of psychological interventions in preventing relapse and recurrence. Clin Psychol Rev 41: 16-26.

33. Schore A (2012) The science of the art of psychotherapy. New York: Norton \& Company.
34. Schlager Andrews E (2013) Resiliency and vulnerability to post-partum depression in acculturating new mothers. Dissertation Abstracts International (UMI No. 3601168).

35. Vliegen N, Luyten P (2008) The role of dependency and self-criticism in the relationship between postpartum depression and anger. Personality and Individual Differences 45: 34-40.

36. Bowlby J (1969) Attachment and loss: Volume 1. Attachment. New York: Basic Books.

37. Bowlby J (1973) Attachment and loss: Volume 2. Separation and anger New York: Basic Books.

38. Bowlby J (1980) Attachment and loss: Volume 3. Loss: Sadness and depression. New York: Basic Books.

39. Kernberg O (1975) Bordeline conditions and pathological narcissism. New York: Jason Aronson.

40. Frederickson J (2013) Co-Creating Change. MO: Seven Leaves Press.

41. Ferenczi S (1920) The further development of an active therapy in psycho-analysis. Further contributions to the theory and technique of psycho-analysis, 198-217.

42. McCullough L (1997) Character Change. Basic Books: New York.

43. Davanloo H (1990) Unlocking the unconscious: selected papers of Habib Davanloo, MD. New York: Wiley.

44. Davanloo H (2000) Intensive short-term dynamic psychotherapy: selected papers of Habib Davanloo. Chichester: Wiley.

45. Davanloo H (2005) Intensive short-term dynamic psychotherapy. In: Kaplan and Sadock's comprehensive textbook of psychiatry. Philadelphia: Lippincot Williams \& Wilkins 2628-2652.

46. Abbass A, Town JM, Driessen E (2012) Intensive short-term dynamic psychotherapy: a systematic review and meta-analysis of outcome research. Harv Rev Psychiatry. 20: 97-108.

47. Anda RF, Felitti VJ, Bremner JD, Walker JD, Whitfield Ch, et al. (2006) The enduring effects of abuse and related adverse experiences in childhood. Eur Arch Psychiatry Clin Neurosci 256: 174-186.

48. Blatt SJ (1995) The destructiveness of perfectionism: Implications for the treatment of depression. Am Psychol 50: 1003-1020. 